\title{
Redes sociales asimétricas en el sistema hortícola del valle de Tepeaca, México
}

\section{Asymmetric social networks in the horticultural system in the Tepeaca Valley, Mexico}

\author{
Diosey Ramón Lugo-Morín \\ JaVIER RAMÍrEZ-JuÁrez \\ José Arturo MÉndez-Espinoza \\ Benjamín Peña-Olvera*
}

\begin{abstract}
This paper examines the negotiation and subordination relationships of small horticultural producers in asymmetric social networks in the horticultural system of the Tepeaca Valley, Puebla, Mexico. Social networks are interstitial spaces where small producers, with a certain degree of autonomy, negotiate the retention of economic surplus with brokers and companies. We conclude that the organisation of the horticultural production system is achieved through asymmetrical social networks, where the small producer establishes trading and subordination relationships that are defined by each type of arrangement.
\end{abstract}

Keywords: asymmetric social networks, horticultural system, social actors, rural Mexico.

\section{Resumen}

En este trabajo se analizan las relaciones de negociación y subordinación de los pequeños productores hortícolas en las redes sociales asimétricas en el sistema hortícola del valle de Tepeaca, Puebla. Las redes sociales son espacios intersticios donde los pequeños productores, a partir de cierta autonomía, negocian la retención de excedentes económicos con intermediarios y empresas. Se concluye que la organización del sistema productivo hortícola se realiza mediante redes sociales asimétricas, donde el pequeño productor establece relaciones de negociación y subordinación que se definen según el tipo de arreglos.

Palabras clave: redes sociales asimétricas, sistema hortícola, actores sociales, México rural.

* Colegio de Postgraduados, Campus Puebla, México. Correos-e: morin@colpos.mx, rjavier@ colpos.mx, jamendez@colpos.mx, bpena@colpos.mx. 


\section{Introducción}

La globalización está reconfigurando el sistema productivo agrícola y rural, modificando los patrones tradicionales de producción en América Latina, pero con diferentes expresiones territoriales que no necesariamente implican el dominio y control de los procesos productivos agrícolas por las transnacionales (Paniagua-Mazorra, 2008; Paz, 2006; Méndez, 2006; Díaz et al., 2006; Iglesias-Piña, 2005; Belo-Moreira, 2004; Robles, 2004; Caravaca et al., 2003; Murdoch, 2000), debido a que se observa el surgimiento de la recomposición agrícola de la agricultura familiar (Ramírez, 2008).

En México la reconfiguración territorial rural está presente en el sistema productivo hortícola del valle de Tepeaca, Puebla. En éste, los pequeños productores han impulsado estrategias de recomposición agrícola, desplazando la tradicional producción de cereales, especialmente de maíz, pero sin abandonarla por completo, por hortalizas que les permiten mejores ingresos. En el sistema de producción hortícola se identifican los componentes: proceso productivo, bienes y servicios agrícolas y comercialización, con la participación de diversos actores sociales y económicos. En el primero participan los pequeños productores; el segundo se compone por proveedores de bienes y servicios agrícolas, y en el tercero, intermediarios locales y empresas comerciales, exportadoras y empacadoras.

La interacción entre los actores sociales ha propiciado pugnas por la apropiación de los excedentes económicos que genera el sistema hortícola, estableciendo relaciones de negociación y subordinación. La apropiación de los excedentes económicos lleva a plantear que se establecen estructuras diferenciadas, en las cuales las redes sociales asimétricas cobran importancia. Este estudio tiene como objetivo analizar las relaciones de negociación y subordinación de los pequeños productores hortícolas en redes sociales asimétricas del sistema hortícola del valle de Tepeaca. El enfoque de redes sociales permite abordar las relaciones de los actores sociales en las interacciones y arreglos que tejen para negociar y apropiarse de los excedentes económicos.

En este marco se realizó el presente estudio, el trabajo de campo se completó en junio-diciembre de 2008. Desde una perspectiva cualitativa se realizaron entrevistas a los comerciantes y agricultores de la Central de Abasto de Huixcolotla; destacando las interrogantes orientadas a identificar las relaciones en el sistema hortícola y la red social de los actores participantes. La información se sistematizó y analizó de acuerdo con las variables de estudio.

El trabajo se divide en tres secciones: en la primera se plantean algunas consideraciones teóricas sobre las redes sociales. En la segunda se señalan 
los principales rasgos de la zona de estudio y la importancia del valle desde el contexto histórico y su posicionamiento geográfico. La tercera sección aborda la importancia de las redes en el ámbito territorial y su configuración desde los actores y sus arreglos. Finalmente, se exponen las conclusiones y la bibliografía que sustentó el estudio.

\section{Las redes sociales}

Las redes sociales son el resultado de la relación de los grupos humanos que sostienen dos o más personas con la finalidad de ayudarse, realizar negocios o llevar a cabo cualquier actividad articulada con sus intereses. Los rasgos familiares, de negocios o de producción son los más comunes de encontrar en las redes sociales que se efectúan entre los integrantes de la sociedad (González y Basaldúa, 2007).

Desde una perspectiva más amplia, Barnes define las redes sociales como "campos sociales constituidos por relaciones entre personas" (1954: 45). Entendiendo campo social, de acuerdo con Lomnitz, como una "construcción abstracta del investigador de acuerdo al criterio que le interese, lo cual permite identificar estructuras sociales que generalmente no están formalmente definidas por la sociedad y que de otra forma no serían identificables" (2001: 342).

Mitchell (1974) define una red como un conjunto particular de interrelaciones entre un conjunto limitado de personas, consideradas como una totalidad, que pueden ser utilizadas para interpretar el comportamiento social de las personas implicadas.

Una visión distinta es la adoptada por Podolny y Baron (1997) y Sparrowe et al. (2001), quienes conceptualizan las redes sociales en términos de información y recursos a los cuales los actores pueden acceder en escenarios competitivos.

En el presente estudio se consideran las redes sociales como un espacio relacional donde los actores sociales construyen relaciones diferenciadas en el marco de múltiples procesos (por ejemplo, de negociación, subordinación, cooperación o conflicto).

En la investigación empírica (Mitchell, 1999; Lomnitz, 2001; Andrews et al., 2002; Bertrand, 2002) se identifican dos tipos de redes sociales: simétricas y asimétricas. Las primeras se forman entre grupos sociales de igual estatus y sus ejes articuladores son el parentesco, la amistad, la vecindad o proximidad geográfica, la religión y las manifestaciones culturales. Las segundas se construyen entre grupos sociales diferenciados y su eje articulador fundamental es la motivación económica.

El planteamiento metodológico que nos ofrecen las redes sociales es propicio para construir un marco analítico de los actores sociales, su 
posición y dinámica relacional en un determinado sistema productivo, particularmente de sus intercambios.

Para comprender el proceso de apropiación por los actores sociales a partir de redes sociales, se utilizó la perspectiva analítica empleada por Lomnitz (2001), considerando la importancia de los recursos (tipo, cantidad, intercambio, articulación). Así, se consideró que el tipo de recurso de los actores sociales del sistema hortícola es diferenciado: los pequeńos productores disponen de tierra, conocimiento y fuerza laboral, y mediante ellos obtienen productos hortícolas con un alto valor comercial; los proveedores de servicios y bienes agrícolas disponen de productos necesarios en la producción, como semillas, agroquímicos, tecnologías, entre otros, y por último el capital comercial (intermediarios locales), empresarial y cadenas de comercio. Éstos últimos disponen de capital y una posición estructural en el sistema hortícola que les permiten tener ventajas en los procesos de negociación y subordinación por el excedente económico.

La cantidad de los recursos se relaciona con la disponibilidad de capital, infraestructura y grado de especialización de cada uno de los actores sociales de la red. La dirección del intercambio de los recursos da cuenta del tipo de relación que establecen los actores sociales, que puede ser asimétrica o simétrica. Lovaglia et al. (1995: 124) señalan la importancia de la cantidad y el flujo de los recursos en el proceso de negociación. Por último, la articulación que comprende los sectores que controlan los recursos en el sistema. Estos elementos son clave en la apropiación y negociación de los excedentes económicos del sistema hortícola del valle de Tepeaca.

\section{El valle de Tepeaca y su evolución productiva}

El valle de Tepeaca ${ }^{1}$ se ubica en el estado de Puebla, México (mapa I). Según el vir Censo Agropecuario 1991 tiene una extensión territorial de 125,973 hectáreas. De acuerdo con Rappo y Vázquez (2006: 36), está conformado por 13 municipios: San Francisco Mixtla, San Isabel Tlalnepantla, Cuautinchán, Tzicatlacoyan, Tecali de Herrera, Acatzingo, San Salvador de Huixcolotla, Tepeaca, Cuapiaxtla de Madero, Tecamachalco, Santo Tomás Hueyotlipan, Tochtepec y Los Reyes de Juárez. Se localiza

\footnotetext{
${ }^{1}$ El valle es un paisaje ubicado en un espacio que debido a los pisos altitudinales posee climas diferentes porque se encuentra entre dos áreas de relieve más alto. Esta variación topográfica y la precipitación originan procesos de remoción y sedimentación en su superficie que influyen positivamente en la calidad del suelo. Los valles conforman el tipo de paisaje más importante del espacio rural mexicano, no por su dimensión espacial, sino porque son el entorno donde se concentra la actividad hortícola de México (Villa et al., 2001; Avendaño y Schwentesius, 2005; Rappo y Vázquez, 2006; Macías, 2008; Avendaño, 2008; Ramírez, 2009).
} 
entre 2,000 y 2,300 msnm. El clima es templado subhúmedo con lluvias en verano, la temperatura promedio varía entre 12 y $16^{\circ} \mathrm{C}$ y las precipitaciones entre 600 y $800 \mathrm{~mm}$, tiene escasa presencia de ríos, sin embargo tiene la peculiaridad de presentar los mayores aprovechamientos de los recursos fluviales, pues su territorio se encuentra surcado por una gran cantidad de canales de riego que se benefician del río Atoyac, el cual pasa por el occidente de la región (Herrera et al., 2003). Las características derivadas de los pisos altitudinales, topografía y el tipo de suelo le otorgan al pequeño productor ventajas agroecológicas para la producción hortícola. Rappo y Vázquez (2006) mencionan que existen alrededor de 20,000 unidades de producción rural (UPR) que ocupan 37,407 hectáreas.

Ramírez (2009) señala que en la región, entre la Colonia y el siglo xxI, se distinguen dos sistemas agrarios asociados al uso, forma de apropiación y control territorial que le han conferido características propias. De acuerdo con Garavaglia y Grosso (1994), durante la Colonia se construyó un sistema agrario de grandes concentraciones de tierra, dedicado a la producción de maíz y trigo. Hacia finales del siglo XviII la región contaba con más de 400 haciendas dedicadas a la producción de maíz, trigo, chile, ovinos y porcinos, orientadas principalmente al abasto de Puebla y, secundariamente, Veracruz.

Este sistema generó conflictos entre los indígenas y los españoles sobre las tierras, que se expresaban en demandas de los pueblos contra los dueños de las haciendas (Olivera, 1978). A principios del siglo xx la región concentraba 147 haciendas y 130 ranchos (Palacios, 1917). Durante la Revolución mexicana no hubo expropiaciones ni repartos de tierra de las haciendas. A finales de los años veinte los peones iniciaron demandas y luchas por la tierra (Nickel, 2004), acción que culminó con la reforma agraria, en la década de 1930, transformando el sistema de apropiación y uso del territorio. Con el reparto agrario se reportan 73 ejidos y 9,123 ejidatarios. De acuerdo con cálculos de Rappo y Vázquez (2006), el índice de campesinidad ${ }^{2}$-metodología desarrollada por Toledo- oscila entre 0.347 y 0.505 , en los 13 municipios están por debajo de 1 , es decir, son municipios campesinos.

Ramírez (2009) señala que con el reparto de tierra comenzó un sistema agrario de pequeñas explotaciones, basado en el trabajo familiar, dedicado a la producción de maíz y frijol, que desplazó la producción de trigo, orientado al autoconsumo y el mercado en el contexto del modelo de sustitución de importaciones. Este sistema agrario permitió a los pequeños productores su reproducción social y económica; no obstante, a

${ }^{2}$ El valor de 0 a 0.39 representa un modo de apropiación campesino; 0.51 a 0.60 , intermedio con tendencia al modo agroindustrial; y de 0.61 a 1 , modo agroindustrial. 


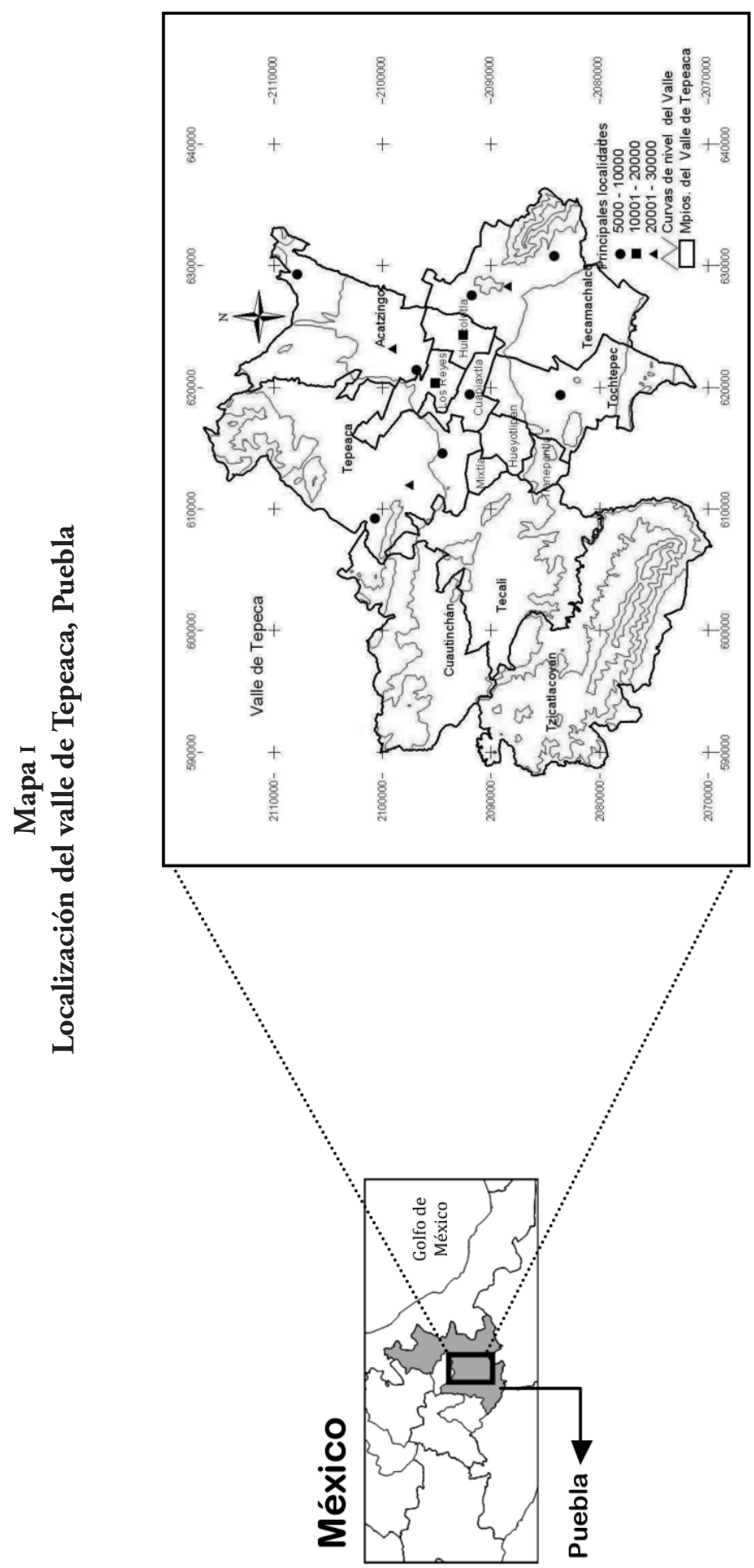

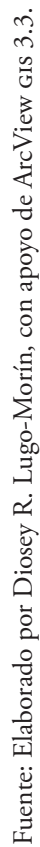


finales de la década de 1960, en medio de la desvaloración de las actividades y de la crisis agrícola, comenzaron acciones colectivas para mejorar sus ingresos con la construcción de sistemas de pequeño riego (González, 1995) y la introducción de cultivos con mayor rentabilidad económica, como las hortalizas y los forrajes, frente a la tradicional producción de maíz, lo que redefinió el sistema agrario

Aun cuando el uso de regadío tiene un origen prehispánico ${ }^{3}$ en la región, fue a partir de la década de 1970 que se profundizó la movilización social del campesinado para construir sistemas de riego, como parte de acciones colectivas que buscaba asegurar y mejorar su reproducción social y económica. No hay estadísticas que registren todos los aprovechamientos hidráulicos, generalmente pozos profundos, pues un gran número no están registrados ni concesionados, como lo establece la Ley de Aguas Nacionales. ${ }^{4}$ De acuerdo con el registro público de derechos de agua de la Comisión Nacional del Agua, en la región existen 512 aprovechamientos, de los cuales en el municipio de Tepeaca se reporta $22.6 \%$, en Tecamachalco 22.7\%, en Tochtepec 14.3\% y en Acatzingo 13.9\%; el 26.5\% restante se distribuye en los demás municipios de la región.

En el valle de Tepeaca el espacio agrícola es diversificado, con alrededor de 40 cultivos cíclicos y perennes, a los que se asocian cultivos con diverso grado de desarrollo fenológico. En 2005 se sembraron 44,987 ha, $46.2 \%$ en riego y $53.8 \%$ en temporal. Destacan el grupo de hortalizas, forrajes y cereales. En menor medida se producen flores y frutales. El valor total de la producción ese año fue cercano a 438 millones de pesos, de los cuales el riego aportó $81 \%$ y el temporal $19 \%$, por lo que es indudable el aporte del riego a la economía regional (cuadro 1). De acuerdo con su importancia, la producción hortícola proviene de los municipios de San Salvador Huixcolotla, Los Reyes de Juárez y Acatzingo.

La producción hortícola tiene efecto regional, nacional e internacional; según información proveniente de los comerciantes de la Central de Abasto, el valor de la producción mensual de hortalizas supera los 30 millones de dólares. El estudio de Hernández y Martínez (2006: 119) informa que la producción de hortalizas fue de 73,292 toneladas en el ciclo 2000-2001,

\footnotetext{
${ }^{3}$ Martínez (1984: 13-14) señala que en el año 1550 ya se reportaba el poco uso de las técnicas de regadío, menciona que en Acatzingo se aplicaba a la horticultura; es probable que el mismo uso tuviera, desde entonces, el sistema de galerías filtrantes conocido en la actualidad en el pueblo de San Hipólito Xochiltenango, al sureste de la ciudad de Tepeaca. La agricultura, entonces, era de temporal, sujeta a las vicisitudes ambientales: una sequía prolongada o la temprana presencia de las heladas a menudo destruía las cosechas. Pero una buena temporada de lluvias producía abundante cosecha y bonanza; semillas de maíz y trigo y otras legumbres.

${ }^{4}$ El artículo 20 establece que de conformidad con el carácter público del recurso hídrico, la explotación, uso o aprovechamiento de las aguas nacionales se realizará mediante concesión o asignación otorgada por el Ejecutivo federal.
} 


\section{Cuadro 1}

Superficie y valor de la producción de los cultivos cíclicos y perennes en el valle de Tepeaca, 2005

\begin{tabular}{lcccr}
\hline \multicolumn{1}{c}{ Cultivos } & $\begin{array}{c}\text { Superficie } \\
\text { sembrada } \\
\text { (ha) }\end{array}$ & Porcentaje & $\begin{array}{c}\text { Valor de la } \\
\text { producción } \\
\text { (miles de pesos) }\end{array}$ & Porcentaje \\
\hline Hortalizas & $7,116.0$ & 15.8 & $225,426.5$ & 51.5 \\
Forrajes & $6,309.0$ & 14.0 & $101,094.6$ & 23.1 \\
Granos básicos & $31,404.5$ & 69.8 & $107,969.2$ & 24.7 \\
Flores & 81.0 & 0.2 & $1,105.4$ & 0.3 \\
Frutales & 76.5 & 0.2 & $2,273.6$ & 0.5 \\
Total & $44,987.0$ & 100 & $437,869.2$ & 100 \\
\hline
\end{tabular}

Fuente: Sagarpa (2006).

\section{Figura I}

\section{Central de Abasto de Huixcolotla, Municipio de San Salvador} Huixcolotla

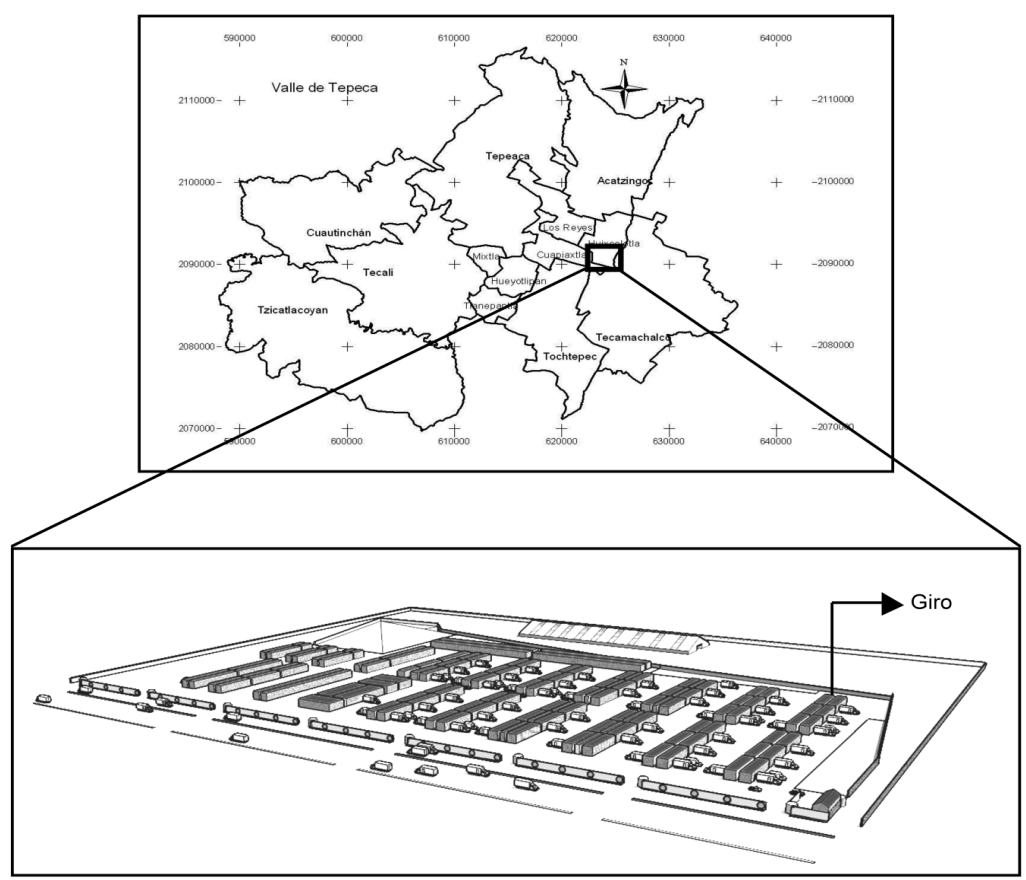

Fuente: Elaborado por Diosey R. Lugo-Morín, con apoyo de ArcView GIS 3.3 y Auto-CAD. 
con un valor cercano a los 131 millones de pesos, comercializado sobre todo en el mercado de San Salvador Huixcolotla (figura I).

En un marco analítico más amplio, Schwentesius y Gómez (1997) y Avendaño (2008) reportan que la participación de las hortalizas en las exportaciones totales de productos agrícolas experimentó un crecimiento de $45 \%$ en 1995 a más de $53 \%$ en el 2005. En México se destina entre 2.8 y $3.7 \%$ de la superficie agrícola a la producción de hortalizas, la cual genera aproximadamente $18 \%$ del valor de la producción agrícola nacional.

La producción hortícola de México está fragmentada en zonas productoras, cuyo móvil de producción y organización están determinados por el mercado final. Así, se distinguen las siguientes formas productivas: 1) producción minifundista, de bajo nivel tecnológico, de verano y otoño, ubicada en los cinturones de las grandes ciudades y zonas cercanas a los grandes centros de población, como los estados de Tlaxcala, Puebla, Hidalgo, etc.; 2) producción comercial de nivel tecnológico medio-alto para el abasto nacional, ubicada en diferentes estados, como Guanajuato, Jalisco, Morelos, San Luis Potosí y otros con gran vinculación con la Central de Abasto del Distrito Federal (CEDA); 3) producción para la exportación en fresco, ubicada en Sinaloa (invierno), Sonora (primavera temprana), Guanajuato (invierno y verano) y Baja California (verano), y 4) producción de hortalizas para su transformación, Guanajuato (brócoli y coliflor) durante todo el año y Sinaloa (pasta de tomate) durante el invierno (Schwentesius y Gómez, 1997; Avendaño, 2008).

En este marco, los pequeños productores hortícolas del valle de Tepeaca participan en un sistema agrícola altamente competitivo, en el que diversos actores sociales establecen relaciones con distintos arreglos.

\section{Las redes en el ámbito territorial}

Los sistemas productivos se pueden ver como mecanismos que influyen en las transformaciones permanentes de las localidades y regiones, tratando de responder a las exigencias del mercado mediante redes sociales en un territorio. De acuerdo con Long, los actores sociales son:

Todas aquellas entidades sociales que tienen agencia (capacidad de conocer y actuar, y la manera en que las acciones y las reflexiones constituyen prácticas sociales que impactan o influyen en las acciones e interpretaciones propias y de los otros) en tanto que poseen la capacidad de conocer, justipreciar situaciones problemáticas y organizar respuestas apropiadas. Aparecen en una variedad de formas: personas individuales, grupos informales o redes personales y organizaciones (2007: 442). 
Díaz et al. (2006) definen el sistema productivo como redes internas que se establecen entre agentes y empresas especializadas en la fabricación de un producto en el ámbito local. Esta relación puede ser formal o informal para intercambiar conocimiento, bienes y servicios. La formal es cuando deliberadamente se plantean acuerdos de cooperación, la informal se refiere a relaciones aisladas y espontáneas, lo cual permite aprovechar las ventajas económicas.

En el sistema hortícola del valle de Tepeaca las redes sociales asimétricas se construyen para producir y comercializar un bien, a partir del cual se establece una disputa y negociación por la apropiación de excedentes económicos que genera el sistema hortícola. En este sentido, Lazega sostiene que los "actores sociales de un colectivo o sistema le dan importancia a la apropiación y a la ganancia exclusivamente individual" (2004: 16-17). El sistema productivo se forma de tres componentes: el proceso productivo agrícola, los bienes y servicios para la producción y la comercialización; los actores sociales presentes en el sistema son los siguientes.

\subsection{Componente 1: proceso productivo}

\subsubsection{Pequeños productores}

Tienen una edad entre 30 y 65 años, con un promedio de 3.5 hectáreas por unidad productiva (Ramírez, 2009). Entre los elementos que la integran destacan: la propiedad de la tierra, el conocimiento local, la fuerza laboral y los recursos económicos que les permite cierta autonomía referente a qué, cuándo, cómo y cuánto producir. La actividad hortícola descansa en la familia, así como la contratación de fuerza de trabajo.

Las condiciones agroecológicas (topografía, clima y calidad del suelo) del valle de Tepeaca favorecen la producción de hortalizas, consideradas el grupo vegetal de importancia comercial más rentable en los ámbitos nacional e internacional (Avendaño, 2008; Macías, 2008). La producción hortícola rentable ha animado a los productores para emprender acciones colectivas para el acceso al riego mediante la perforación de pozos. Para Ostrom y Ahn (2003) y Crozier y Friedberg (1990) las motivaciones económicas son un elemento central para concretar los arreglos que surgen al interior del sistema. 


\subsection{Componente 2: bienes y servicios agrícolas}

\subsubsection{Casas comerciales}

Son comerciantes que viven en la región, en la mayoría de los casos son profesionistas de la agronomía, lo cual les permite eventualmente proporcionar asistencia técnica a los agricultores, como incentivo para la compra de los agroquímicos (fertilizantes, plaguicidas, minerales) y semillas. Por su proximidad geográfica con las zonas productoras de hortalizas, tienen contacto permanente con los pequeños productores, en ocasiones establecen alianzas con organizaciones gubernamentales para distribuir bienes e insumos de los programas de desarrollo rural.

\subsubsection{Viveros}

Proporcionan al pequeño productor plántulas de hortalizas en cantidades que varían según el tamaño del predio. En su mayoría, los viveros se ubican en los municipios de San Salvador Huixcolotla, Los Reyes de Juárez y Acatzingo. El funcionamiento de los viveros lo regula el Servicio Nacional de Inspección y Certificación de Semillas, organismo que depende de la Secretaría de Agricultura, Ganadería, Desarrollo Rural, Pesca y Alimentación (Sagarpa).

\subsubsection{Despachos de certificación sanitaria}

Se trata de personas morales o físicas encargadas de inspeccionar y certificar los productos hortícolas, según las normas de sanidad internacional para la exportación y reguladas por la Sagarpa. Proveen servicios a las empresas empacadoras, en general se componen por jóvenes profesionales, con una edad promedio de 30 años, que viven en la región y tienen una proximidad geográfica con las empresas empacadoras. Dependiendo del tamaño del despacho en términos de personal, pueden realizar entre cuatro o cinco inspecciones-certificación.

\subsubsection{Organizaciones gubernamentales}

Las instancias gubernamentales tienen poca presencia en el sistema hortícola de la región, sus apoyos son puntuales (por ejemplo, Procampo). Las instituciones que tienen presencia en el valle de Tepeaca son la Secretaría de la Reforma Agraria (SRA), la Secretaría de Desarrollo Rural (SDR) 
y la Sagarpa. En todos los casos operan mediante programas de desarrollo rural y oficinas de atención al agricultor. ${ }^{5}$

\subsection{Componente 3: comercialización de la producción bortícola}

Este componente agrupa dos tipos de capital: el comercial, ${ }^{6}$ con intermediarios locales, y el empresarial, ${ }^{7}$ con empacadoras y exportadoras, así como cadenas de comercio.

\subsubsection{Intermediarios locales}

Localmente se les denomina intermediarios o coyotes, operan con capital comercial, es un sector que vive en la región, con un conocimiento del sistema productivo, especialmente de los agricultores, que les permite establecer acuerdos de comercio. Poseen recursos económicos para transacciones diarias, son dueños de medios de transporte y pueden o no poseer tierras. Su origen en el valle de Tepeaca se debe a la recomposición económica que ha sufrido la región en los últimos años, con la especialización del trabajo por rama productiva, como se presenta en el siguiente testimonio:

He sido productor por más de 35 años en Acatzingo, en esta zona sembraba mucho maíz y frijol, estos cultivos ya han decaído, hace más de 15 años que se empezó con las legumbres, yo sembraba cebolla, col y jitomate. Pero los costos para producir han subido mucho y no tenemos apoyo del gobierno, ante eso sale mejor comprar legumbres que producirlas. Yo vendo en Huixcolotla cebolla, casi toda la cebolla se la compro a los productores locales y también compro a los productores de Guanajuato, Sinaloa, Morelos y Chihuahua.

(Raúl, 52 años, Acatzingo, diciembre de 2008)

Estos actores, debido al conocimiento del ámbito regional y su experiencia, ubican a los pequeños productores en sus predios, establecen arreglos de compras inmediatas y negocian el precio. Este sector no rea-

\footnotetext{
${ }^{5}$ Entre los aspectos que se consideran para explicar la ausencia de las instituciones gubernamentales se encuentran: "la desinformación de la población rural, la desorganización e incipiente democratización de las decisiones sobre los destinos y usos de los recursos públicos, una gerencia pública que se encuentra impregnada de intereses político-partidistas que restringen o utilizan de manera unilateral los apoyos al campo dependiendo de las coyunturas electorales y las reglas de operación de los programas que terminan siendo un gran obstáculo para el acceso a los apoyos que promueven, ya que los beneficios siguen concentrándose en un sector de la sociedad rural que sí puede reunir los requisitos y recursos complementarios que la actual política de desarrollo rural exige” (Herrera, 2009: 36).

${ }^{6}$ El capital comercial es aquél que permite soportar las transacciones de compra-venta de productos sin realizar inversión.

${ }^{7}$ El capital empresarial no sólo soporta las operaciones de compra-venta de productos, sino que también se emplea para realizar inversiones (infraestructura, tecnología y transporte).
} 
liza inversiones productivas y vende la producción a pequeños y medianos comercios en la región y la Central de Abasto de Huixcolotla.

\subsubsection{Empresas empacadoras y exportadoras}

Este sector posee un alto capital económico e infraestructura. Se localiza en los municipios más importantes de la región (Acatzingo, Huixcolotla y Los Reyes) y en la cercanía de la Central de Abasto de Huixcolotla. Según el padrón que maneja el Consejo de Horticultores de Puebla a la Intemperie, existen más de 40 empresas empacadoras en la región y exportan a los países que conforman el Tratado de Libre Comercio de América del Norte (TLCAN). Se vinculan a la producción mediante agricultores que tienen un liderazgo regional para establecer compromisos de compra-venta. Para posesionarse en el mercado regional, algunas empresas rentan bodegas en los municipios con mayor producción hortícola. Demandan hortalizas de excelente calidad ofreciendo los mejores precios, de acuerdo con lo dicho por los pequeños productores.

\subsubsection{Empresas comerciales}

Se conocen en la región como cadenas de comercio o comercializadores, tienen capital e infraestructura y pueden o no pertenecer a la región. Compran grandes volúmenes de hortalizas en representación de cadenas comerciales transnacionales y nacionales, como Wal-Mart, Costco y Chedraui, entre otras. Establecen normas de calidad en las hortalizas y por los volúmenes que demandan fijan precios de compra con reducido margen de negociación para los pequeños productores.

\subsection{Los arreglos en las redes sociales asimétricas}

Los actores sociales que integran el sistema hortícola del valle de Tepeaca se estructuran de manera diferenciada, con diverso poder económico, a partir de lo cual los pequeños productores establecen relaciones de negociación y subordinación con los proveedores de insumos cuando adquieren agroquímicos y semillas, pues al mismo tiempo les ofrecen asistencia técnica. El siguiente testimonio muestra este tipo de relación.

Yo no recibo asistencia técnica para el manejo de mi cultivo que es el huauzontle, quien me ayuda es el de la casa comercial. Cuando tengo un problema con la siembra tomo una planta de muestra y le digo que me venda algo económico, el de la casa comercial me recomienda un producto que él vende, y el producto sí funciona pero sólo por un tiempo, cuando deja de ser efectivo, regreso nueva- 
mente y el dueño me recomienda otro producto que en la mayoría de los casos es más caro que el anterior.

(Alfredo, 30 años, Los Reyes de Juárez, noviembre de 2008)

Los pequeños productores establecen relaciones de negociación y lealtad con los productores de plántula de los viveros, pues tienen la opción de pagar de manera diferida la plántula, lo cual puede ser hasta que venden la cosecha. Otras relaciones que establecen los viveros son de cooperación con el Servicio Nacional de Inspección y Certificación de Semillas, organismo que depende de la Sagarpa, encargado de regular el funcionamiento de los viveros como medida de control sanitario y certificación de materiales vegetales.

Con los intermediarios y empresas, los pequeños productores establecen relaciones de negociación y subordinación en cuanto a los excedentes económicos del sistema hortícola, a través de los precios. A partir de las relaciones y cadena de valor de la producción de hortalizas, los pequeńos productores se apropian entre 20\% y $35 \%$ del valor de la producción; por ejemplo para la cadena de valor del huauzontle, el valor porcentual en cada eslabón puede variar en alrededor de 5\% (figura II), con una participación o apropiación del valor de la producción por los productores de $20 \%$, distribuido entre costos de producción e ingresos netos por hectárea cosechada al mes. El eslabón que se apropia de un mayor valor corresponde a empresas que destinan el producto al mercado estadounidense. De acuerdo con Avendaño y Schwentesius (2005: 180), los agentes comercializadores pueden apropiarse de $70 \%$ de la cadena de valor en la producción de hortaliza, mediante la comercialización por mayoreo y menudeo.

\section{Figura II}

Distribución porcentual de la cadena de valor del huauzontle

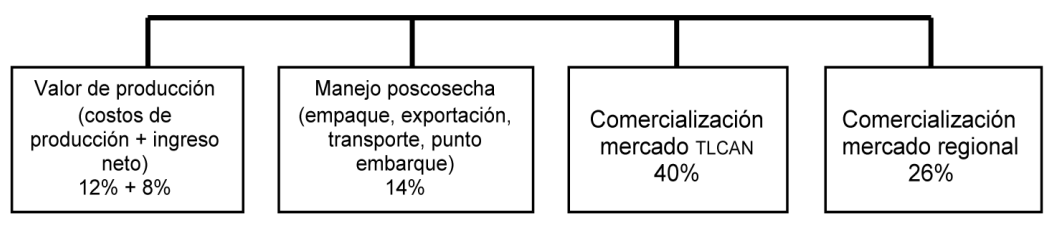

Fuente: Elaboración propia a partir de los datos de campo recopilados en junio-diciembre de 2008.

El destino de la producción son los mercados regionales y nacionales, donde la central de abasto de Huixcolotla es el principal centro de intercambio, así como Estados Unidos y Canadá. 
Un cultivo que se está desarrollando es el de huauzontle (Chenopodium nuttalliae), que en los últimos 10 años se ha posicionado en el mercado de Estados Unidos. Debido a sus propiedades nutritivas y medicinales, se ha incrementado la superficie sembrada (Heiser y Nelson, 1974; Bhargava et al., 2007). El cultivo de huauzontle en el municipio de Los Reyes de Juárez es escalonado, tres veces al año con cortes semanales de una tonelada por ha, obteniendo un volumen anual de producción por ha de 48 toneladas, con un valor que oscila entre dos y cinco pesos por kilo, dependiendo de la calidad del producto. La producción se vende a Comercializadora Mexicana de Legumbres, s.a. de c.v. (empresa empacadora), ubicada en Acatzingo, se calcula que 50\% se exporta a Texas, Atlanta, Houston y California, la producción restante se comercializa en la Central de Abasto de Huixcolotla. Otros cultivos representativos del valle son: cebolla (Allium cepa), cilantro (Coriandrum sativus) y brócoli (Brassica oleracea). El valor de la producción en 2007 fue de 9.6, 8.5 y 7 millones de pesos, respectivamente (Sagarpa, 2008), la producción se concentra en los municipios de Los Reyes de Juárez, Tepeaca, Tecamachalco, Cuapiaxtla de Madero y Acatzingo.

Para estos cultivos se presentan tres tipos de comercialización: la venta en la Central de Abasto, la venta a los intermediarios locales y la venta a empresas empacadoras y exportadoras. En la Central de Abasto se agrupa por cultivos (en un área específica, en el cual los productores pagan un impuesto de 50 pesos), allí concurren intermediarios, revendedores y consumidores que negocian y acuerdan los precios a partir de la oportunidad de las cosechas en los mercados regional y nacional y la calidad del producto. La Central es un espacio de negociación por la apropiación de los excedentes económicos, favorable y/o limitativa para los pequeńos productores, dependiendo de las circunstancias específicas del mercado.

En el segundo caso, los pequeños productores hacen arreglos con los intermediarios locales, que se realizan las más de las veces en los predios de los productores y en menor proporción en la Central de Abasto de Huixcolotla, en ambos casos los márgenes de retención de los excedentes para los pequeños productores están sujetos a la demanda de mercado, la calidad de los productos y las necesidades económicas del productor.

En el tercer caso, los pequeños productores hacen arreglos con las empresas empacadoras, exportadoras y comerciales, éstos generalmente les son favorables al permitirles márgenes de ingresos por encima de los costos de producción.

Los pequeños productores son parte de una red social, dentro de la cadena de valor hortícola, para la venta de su producción, constituyen el eslabón primario sujeto al poder económico de intermediarios y de las empresas empacadoras, exportadoras y comerciales. Este poder económi- 
co les permite apoderase de los excedentes económicos en la cadena de valor y subordinar a los pequeños productores, con lo cual se forma una red social asimétrica.

Sin embargo, entre los agentes que intervienen en la comercialización existen disputas por el control del mercado, sin un claro dominio de un sector o agente, que permite a los pequeños productores negociar un mejor precio, dependiendo de la calidad del producto y de la oferta en otras regiones productoras. Asimismo, para el pequeño productor hortícola, la posibilidad de obtener ganancias es un proceso social construido de ensayo y error, no determinada únicamente por un ciclo productivo, sino por dos o tres donde ensaya diversos cultivos y condiciones de mercado, un ciclo puede perderse, sin la posibilidad de recuperar los costos de producción, pero al siguiente o próximos obtener ingresos que le permiten capitalizarse, lo cual, por ejemplo, se traduce en la compra de vehículos nuevos u otros bienes.

La presencia e importancia de las redes sociales asimétricas han sido estudiadas por Barnes (1954), Crozier y Friedberg (1990) y Varanda (2007) desde una perspectiva estructural y considerando el margen de incertidumbre de los actores sociales, pero no explican de manera detallada cómo se generan estas redes asimétricas. Sin embargo, Crozier y Friedberg (1990) señalan la relevancia que tienen los recursos o la capacidad de controlarlos para imponerse a los demás; situando la acción colectiva o individual en un marco estructurado de relaciones de poder y dependencia. En este sentido, Long $(2007,1998)$, Lazega (2004) y Lomnitz (2001) sostienen que los actores sociales, aun cuando pertenezcan a algún colectivo o sistema, le dan importancia a la apropiación y a la ganancia exclusivamente individual, lo cual genera relaciones diferenciadas.

\section{Conclusiones}

Históricamente, la organización del sistema productivo hortícola se ha construido configurando el territorio mediante relaciones y redes sociales. En el sistema hortícola y en la cadena de valor participan diversos actores económicos: pequeños productores, proveedores, intermediarios y empresas. Éstos realizan intercambios de bienes y servicios generando una red social asimétrica sobre la base de relaciones de subordinación y negociación.

Los pequeños productores, dentro de la cadena de valor hortícola, constituyen el eslabón primario y están sujetos al poder económico de intermediarios y de empresas empacadoras, exportadoras y comerciales. Este poder les permite apoderase de los excedentes económicos en la cadena de valor y subordinarlos. Sin embargo, los pequeños productores, a partir de cierta autonomía sobre el proceso productivo hortícola en cuan- 
to a qué, cuándo y cómo producir, negocian la retención de los excedentes económicos por medio de un proceso social construido de ensayo y error de la producción, no determinada únicamente por un ciclo productivo, sino por varios ciclos donde se ensayan diversos cultivos y condiciones de mercado. Esto se expresa en la posibilidad de pérdidas económicas en un ciclo, sin recuperar los costos de producción, pero al siguiente puede obtener ingresos que le permiten capitalizarse.

Los actores sociales imponen y negocian la apropiación de los excedentes económicos, en la esfera de la circulación de la producción hortícola. El estudio identifica actores diferenciados donde la creciente participación de las empresas reconfigura y dinamiza económicamente el valle de Tepeaca. En este marco, los pequeños productores aprovechan espacios intersticios para establecer arreglos y negociar la retención de excedentes económicos que, a su vez, se favorece por la diversidad de los compradores, así como su cercanía a mercados y grandes centros de consumo en Puebla, el Distrito Federal, el sureste mexicano y el mercado internacional.

En el caso de estudio los resultados permiten constatar la recomposición agrícola, en particular el sistema productivo hortícola del valle. El paso de cultivos tradicionales a otros de alta rentabilidad comercial es un aspecto significativo que ha generado sociedades rurales asimétricas en la que pequeños productores e intermediarios-empresas construyen relaciones en una atmósfera de arreglos, intereses y necesidades económicas. En este sentido, el posicionamiento del cultivo de huauzontle en el municipio de Los Reyes de Juárez, el cilantro en Acatzingo y el brócoli en San Salvador Huixcolotla ejemplifican lo señalado. La recomposición ha originado escenarios positivos para los pequeños productores, pero contradictoriamente también ha generado forcejeos y ajustes en las posiciones estructurales de los actores sociales que profundizan la diferenciación social donde el poder económico pasa a ser el elemento articulador del sistema.

Las evidencias empíricas muestran que en la agricultura familiar del valle de Tepeaca participan distintos actores sociales, estructuralmente diferenciados con diverso poder económico, con los cuales establecen relaciones de negociación y subordinación. Los pequeños productores se encuentran en la base de este sistema. Estos aspectos permiten reconocer que las redes sociales asimétricas son fundamentales en la reconfiguración del territorio rural con la finalidad de apropiarse de los excedentes económicos que generan los sistemas de cultivos, además de que representan una vía que nos permite identificar las regularidades en la composición y establecimiento de una dinámica relacional entre los actores. 


\section{Bibliografía}

Andrews, Steven, Carleen Basler y Xavier Coller (2002), "Redes, cultura e identidad en las organizaciones”, REIS, 97, Madrid, pp. 31-56.

Avendaño Ruiz, Belem (2008), "Globalización y competitividad en el sector hortofrutícola: México, el gran perdedor”, El Cotidiano, 23 (147), México, pp. 91-98.

Avendaño Ruiz, Belem y Rita Schwentesius (2005), "Factores de competitividad en la producción y exportación de hortalizas: el caso del valle de Mexicali, B. C., México", Problemas del Desarrollo, 36 (140), México, pp. 165-192.

Barnes, John (1954), "Class and committees in a Norwegian Islan Parish", Human Relations, 7, Londres, pp. 39-58.

Belo-Moreira, Manuel (2004), “The new territorialisation of rural space in the globalization context: entrepreneurship in marginalized areas", Agricultura, Sociedad y Desarrollo, 1, México, pp. 85-100.

Bertrand, Michel (2002), "Élites y redes sociales en Guatemala en tiempos de la independencia”, en M. Bertrand (coord.), Configuraciones y redes de poder, Tropykos, Caracas, pp. 111-132.

Bhargava, Atul, Sudhir Shukla, Shailendra Rajan y Deepak Ohri (2007), "Genetic diversity for morphological and quality traits in quinoa (Chenopodium quinoa Willd) germplas", Genetic Resources and Crop Evolution, 54, Gatersleben, pp. 167-173.

Caravaca, Inmaculada, Gema González y Rocío Silva (2003), "Redes e innovación socioinstitucional en sistemas productivos locales", Boletín de la AGE, 36, Madrid, pp. 103-115.

Crozier, Michel y Erhard Friedberg (1990), El actor y el sistema: las restricciones de la acción colectiva, Alianza, México.

Díaz, Elizabeth, Rodrigo Sánchez y Diana Guadarrama (2006), "La actividad artesanal textil de Guadalupe Yancuictlalpan. ¿Un sistema productivo local?”, Quivera, 8 (2), Toluca, pp. 210-230. 
Garavaglia, Juan Carlos y Juan Carlos Grosso (1994), Puebla desde una perspectiva microhistórica: Tepeaca y su entorno agrario: población, producción e intercambio (1740-1870), Claves Latinoamericanas, México.

González, Ángel (1995), “Manejo de los recursos y producción agrícola en un sistema de pequeña irrigación, caso Buenavista de Juárez, Puebla”, tesis de maestría, Colegio de Postgraduados, México.

González, Carmen y Manuel Basaldúa (2007), "La formación de redes sociales en el estudio de actores y familias. Perspectivas de estudio en historia y antropología", Redes. Revista Hispana para el Análisis de Redes Sociales, 12 (8), Barcelona, pp. 1-27.

Heiser, Charles y David Nelson (1974), "On the origin of the cultivated chenopods (Chenopodium)”, Genetics, 78, Bethesda, pp. 503-505.

Hernández, José Álvaro y Beatriz Martínez (2006), “Género, empoderamiento y movimientos sociales: la unión campesina Emiliano Zapata vive, en la región Tepeaca-Tecamachalco, Puebla”, Región y Sociedad, xviII (36), Hermosillo, pp. 107-146.

Herrera Tapia, Francisco (2009), "Apuntes sobre las instituciones y los programas de desarrollo rural en México. Del Estado benefactor al Estado neoliberal", Estudios Sociales, XVII (33), Hermosillo, pp. 7-39.

Herrera, Lucino, Mauro Cuervo y Enrique Ortiz (2003), "Regiones naturales y de planeación para el estado de Puebla”, Análisis Económico, XVIII (37), México, pp. 257-296.

Iglesias-Piña, David (2005), "Los sistemas productivos como estrategia de desarrollo local ante la globalización", Aportes, x (30), Puebla, pp. 33-50.

Lazega, Emmanuel (2004), "Racionalidad, disciplina social y estructura", Redes. Revista Hispana para el Análisis de Redes Sociales, 5 (6), Barcelona, pp. 1-36.

Lomnitz, Larissa (2001), Redes sociales, cultura y poder: ensayos de antropología latinoamericana, FLACSO-Miguel Ángel Porrúa, México. 
Long, Norman (1998), "Cambio rural, neoliberalismo y mercantilización: el valor social desde una perspectiva centrada en el actor", en S. Zendejas y P. de Vries (eds.), Las disputas por el México rural. I. Actores y campos sociales, El Colegio de Michoacán, México, pp. 45-71.

Long, Norman (2007), Sociología del desarrollo: una perspectiva centrada en el actor, El Colegio de San Luis-CIESAS, México.

Lovaglia, Michael, John Skvoretz, David Miller y Barry Markovsky (1995), "Negotiated exchanges in social networks", Social Forces, 74 (1), Chapel Hill, pp. 123-155.

Macías, Alejandro (2008), "Costos ambientales en zonas de coyuntura agrícola. La horticultura en Sayula (México)", Agroalimentaria, 26, Mérida, pp. 103-108.

Martínez, Hildeberto (1984), Tepeaca en el siglo XVI: tenencia de la tierra y organización de un señorio, CIESAS, México.

Méndez, Ricardo (2006), "La construcción de redes locales y los procesos de innovación como estrategias de desarrollo rural", Problemas del Desarrollo, 37 (147), México, pp. 217-240.

Mitchell, Clyde (1974), "Social networks", Annual Review of Anthropology, 3, Santa Cruz, pp. 279-299.

Mitchell, Clyde (1999), "Orientaciones teóricas de los estudios urbanos en África”, en M. Banton (comp.), Antropología social de las sociedades complejas, Alianza, Madrid, pp. 53-81.

Murdoch, Jonathan (2000), "Networks-a new paradigm of rural development”, Journal of Rural Studies, 16, Londres, pp. 407-419.

Nickel, Herbert (2004), "Los trabajadores agrícolas en la Revolución mexicana (1910-1940): algunas hipótesis y datos sobre la participación y la no participación en los Altos de Puebla-Tlaxcala", en Friedrich Katz (comp.), Revuelta, rebelión y revolución. La lucha rural en México del siglo XVI al siglo XX, Era, México. 
Olivera, Mercedes (1978), Pillis y macehuales: las formaciones sociales y los modos de producción de tecali del siglo XII al XVI, Ediciones de la Casa Chata, México.

Ostrom, Elinor y T. K. Ahn (2003), "Una perspectiva del capital social desde las ciencias sociales: capital social y acción colectiva”, Revista Mexicana de Sociología, 5 (1), México, pp. 155-233.

Palacios, Enrique (1917), Puebla: su territorio y sus habitantes, Secretaría de Fomento, México.

Paniagua-Mazorra, Ángel (2008), "La individualización del mundo rural. Dimensiones analíticas para ¿un concepto generalizable?”, Economía, Sociedad y Territorio, viII (27), Toluca, pp. 639-659.

Paz, Raúl (2006), "El campesinado en el agro argentino: ¿̨repensando el debate teórico o un intento de reconceptualización", European Review of Latin American and Caribbean Studies, 81, Ámsterdam, pp. 65-85.

Podolny, Joel y James Baron (1997), "Resources and relationships: social networks and mobility in the workplace", American Sociological Review, 62 (5), Nashville, pp. 673-693.

Ramírez, Javier (2008), "Ruralidad y estrategias de reproducción campesina en el valle de Puebla, México", Cuadernos Desarrollo Rural, 5 (60), Bogotá, pp. 37-60.

Ramírez, Javier (2009), "Recomposición agrícola del campesinado en el valle de Tepeaca”, en Guillermo Ferro y Fabio Lozano (eds.), La configuración de los territorios rurales en el siglo XXI, Pontifica Universidad Javeriana, Bogotá (en prensa).

Rappo, Susana y Rosalía Vázquez (2006), La construcción del desarrollo sustentable en la región centro-oriente de Puebla, Benemérita Universidad Autónoma de Puebla, Puebla.

Robles, Josefina (2004), "Sistemas productivos locales incompletos: vacíos relacionales en el subsector alimentario de la delegación Azcapotzalco", Análisis Económico, xIx (40), México, pp. 245-268. 
Sagarpa (Secretaría de Agricultura, Ganadería, Desarrollo Rural, Pesca y Alimentación) (2006), Anuario estadistico de la producción agricola y pecuaria 2005, Sagarpa, México.

Sagarpa (Secretaría de Agricultura, Ganadería, Desarrollo Rural, Pesca y Alimentación) (2008), Estadisticas de la producción agrícola por municipio-SIAP, Sagarpa, México.

Schwentesius, Rita y Manuel Ángel Gómez (1997), “Competitividad de la producción hortícola mexicana en el mercado norteamericano. Tendencias a tres ańos del TLC", ponencia presentada en el xx International Congress of the Latin American Studies Association, Guadalajara, México.

Sparrowe, Raymond, Robert Liden, Sandy Wayne y Maria Kraimer (2001), "Social networks and the performance of individuals and groups", Academy of Management Journal, 44 (2), pp. 316-325.

Varanda, Marta Pedro (2007), "Acção colectiva entre pequenos empresários: uma análise de redes sociais”, Análise Social, XLII (182), Lisboa, pp. 207-230.

Villa, María Magdalena, Marco Inzunza y Ernesto Catalán (2001), "Zonificación agroecológica de hortalizas involucrando grados de riesgo", Terra Latinoamericana, 19 (1), México, pp. 1-7.

Recibido: 14 de octubre 2008. Reenviado: 10 de agosto de 2009. Aceptado: 17 de agosto de 2009.

Diosey Ramón Lugo-Morín. Es doctorando por el Colegio de Postgraduados, Campus Puebla, donde también obtuvo la maestría en ciencias agrícolas; hizo la licenciatura en la Universidad Central de Venezuela (ucv), donde obtuvo el grado de ingeniero agrónomo en la especialidad de desarrollo rural. Realizó una estancia doctoral en el Centro de Investigación en Sociología Económica y de las Organizaciones (ISEG/Universidad Técnica de Lisboa) en Portugal. Actualmente es investigador nivel candidato en el Programa de Promoción de Investigadores (PPI) y miembro investigador de la Red Venezolana de Conocimiento Económico del Banco Central de Venezuela. Su línea de investigación actual es redes sociales en el medio rural. Entre sus publicaciones más recientes destacan: 
"Etnocompetitividad del sistema artesanal textil Mitla, el papel del territorio y la innovación”, Economía, Sociedad y Territorio, viII (28), El Colegio Mexiquense, Toluca, pp. 981-1006 (2008); "Evaluación de la vulnerabilidad a la degradación agroambiental a través del uso del sistema microleis en los suelos de los llanos centrales de Venezuela", Revista Internacional de Contaminación Ambiental, 25 (1), unAM, México, pp. 43-60 (2009).

Javier Ramírez-Juárez. Es doctor y maestro en ciencias agrícolas por el Colegio de Postgraduados; licenciado por la Universidad Autónoma Chapingo (UACH). Actualmente es investigador nivel II en el Sistema Nacional de Investigadores ( $\mathrm{SNI}$ ) y líder de la línea de investigación desarrollo rural sustentable del Colegio de Postgraduados. Sus líneas de investigación actuales son: sujetos sociales en el desarrollo rural territorial, ruralidad y campesinado. Entre sus publicaciones destacan: en coautoría, "Etnocompetitividad del sistema artesanal textil Mitla, el papel del territorio y la innovación”, Economía, Sociedad y Territorio, vIII (28), El Colegio Mexiquense, Toluca, pp. 981-1006 (2008); "El sistema de usos y costumbres bajo el poder económico y político local en Matatlán, Oaxaca”, en J. Hernández (coord.), Ciudadanias diferenciadas en un estado multicultural, México, Siglo XXI, México, pp. 131-150 (2007).

José Arturo Méndez-Espinoza. Es doctor en ciencias en geografía por la Universidad de Barcelona; es maestro en ciencias por el Colegio de Postgraduados; hizo la licenciatura en la Benemérita Universidad de Puebla, donde obtuvo el grado de economista. Actualmente es investigador nivel candidato en el Sistema Nacional de Investigadores (SNI). Sus líneas de investigación actuales son: los procesos de transformación agroproductiva de las áreas rurales, estrategias de reproducción campesina y migración. Entre sus publicaciones destacan: Transformaciones agrarias y estrategias de reproducción campesina en el Soconusco, Chiapas, Colegio de PostgraduadosFomex-Chiapas-El Errante Editor, Puebla, México (2007).

Benjamín Peña-Olvera. Es Ph. D por la Iowa State University; es maestro en ciencias por el Colegio de Postgraduados; hizo la licenciatura en la Escuela Superior de Agricultura Antonio Narro donde obtuvo el grado de ingeniero agrónomo. En la actualidad es profesor-investigador titular del Colegio de Postgraduados, donde ha dirigido el trabajo de investigación de tesis de nueve estudiantes graduados como maestros en ciencias y siete como doctores en ciencias. Como producto de sus actividades se han publicado siete artículos en revistas científicas, 25 publicaciones técnicas, siete publicaciones en memorias de eventos científicos y autor 
principal, coautor y/o editor de ocho libros. En su desarrollo profesional ha combinado las actividades de docencia, investigación, servicio y administración. Ha desarrollado experiencia en el diseño, financiamiento, instrumentación y evaluación de programas de desarrollo agrícola y rural a nivel nacional e internacional. 